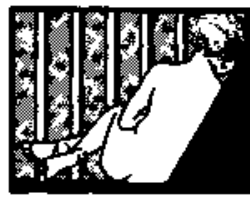

\title{
O trabalhador social e as instituições jurídicas
}

\section{Marta Cristina Ortlz}

Setor de Psicologia de Vara de Menores, em São Paulo.

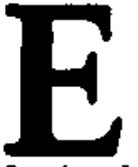

ste texto pretende explorar um pouco as questões do trabalho social, em especial daquele realizado pela Justiça de Menores. Colocar no papel uma série de questões que nos incomodam quando praticamos o trabalho social é tarefa muito difícil, principalmente quando estamos no âmbito de uma instituição como esta. Há uma acentuada rigidez de sua estrutura. Ela tem caráter jurídico, ou seja, uma funçāo normativa. Ela deve ser um instrumento de controle em sentido estrito, dispondo de métodos que vão desde a advertência às puniçōes. A utilização de técnicas psicológicas e de serviço social deve servir à promoção da vigência do Código de Menores - sendo que "vigência" não significa, necessariamente, conformidade, como veremos adiante.

A Justiça de Menores exerce o controle direto sobre a família através de dois tipos de medidas: 1) medidas relativas ao pais ou responsáveis: medidas terapêuticas, advertências, suspensão e destituição do pátrio-poder; 2) medidas relativas aos menores: terapias, orientações, liberdade vigiada, busca e apreensão, internação, desinternaçāo, colocação em lares substitutos. Depois do fracasso dos tratamentos mais liberais, recorre-se às medidas punitivas. No adulto, o controle se dá pela gestão do pátrio-poder; nos menores, pela gestão de sua liberdade.

O Código de Menores de 1979 pretende inaugurar uma nova era na justiça menorista do Brasil. Ele corresponde a um esforço de determinadas correntes jurídicas, no sentido de sobrepor uma visão "científica" e democratizante d̀ antiga imagem de uma instituição policialesca, que chegava a

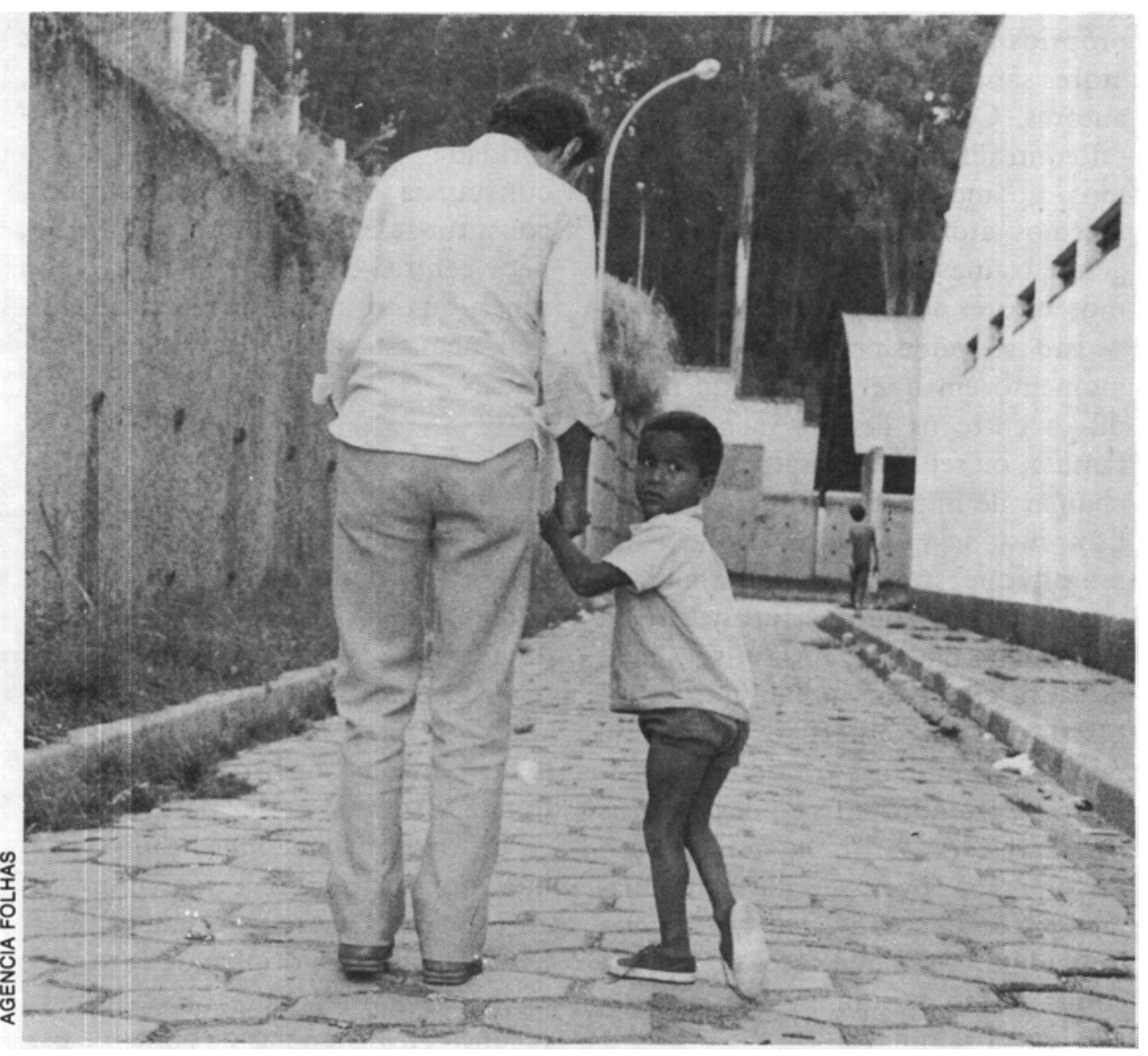

ter, inclusive, seus próprios cárceres - mais tarde encampados pela Previdência Social. Pretendeu-se modificar sobretudo as formas de atendimentos à populaçāo, atentando para a importância do trabalho de peritos técnicos (assistente social e psicólogo), no sentido de melhorar a imagem da instituição e, por conseguinte, promover uma maior penetração do Poder Judiciário no âmbito das relações familiares. Esta democratização dos métodos da Justiça de Menores, porèm, não retira totalmente o seu caráter coercitivo; apenas o torna mais criterioso, cuidadoso, científico.

O técnico é sempre o representante do juiz, melhor dizendo, é o seu maior instrumento de poder. Nem sempre, porém, ambós são convincentes em seus critérios de avaliação e julgamento. Nestes casos, os procedimentos judiciais é que vão definir o encaminhamento do caso e eles, em geral, acabam por limitar o poder do técnico e favorecer o poder do juiz.

Mesmo quando é concedido ao técnico espaço suficiente para atuar com uma certa dose de autonomia, encontra-se um outro obstáculo: o técnico se vê despreparado para lidar com a natureza de muitos problemas apresentados, tanto do ponto de vista da instituição em si, quanto do ponto de vista da população atendida. A potência do técnico é extremamente reduzida, na medida em que seus ins- 
trumentos de intervenção são, em geral, engendrados dentro de um modelo de família burguesa.

\section{Do poder do pal a liberdade do individuo}

De um modo geral, costumamos afirmar que as estratégias familiares são sempre traçadas fora da família. Entretanto, há evidências de que as relações familiares sảo scripts que ora se repetem, ora são subvertidos deliberadamente ou não - por seus próprios atores. Mais do que isso, os atores são, de uma forma ou de outra, autores. Como, porén, entendermos tal contradição? De que forma podemos, ao mesmo tempo em que nos fazemos atores através das personagens e tramas pré-escritas, nos tornarmos autores de nosso próprio drama?

Isto só pôde ocorrer a partir do momento em que o poder do pai se diluiu entre os demais membros da família; ou seja, através do que vamos chamar de implantação do superego. Esta instância psíquica da lei e da moral, que só pode ser formada a partir do confronto e introjeção da autoridade paterna, tornou-se a base da autonomia do indivíduo. $\mathrm{A}$ implantação do superego significou também a implantação da culpa, enquanto regulador interno das práticas singulares. A partir da implantação do superego, pode-se falar tranqüilamente em liberdade, em autonomia individual, sem que isso se choque com a noção de submissão às estratégias extra-familiares

O complexo de Édipo passa a ser, portanto, a coluna vertebral no desenvolvimento da individualidade. Ao longo de todo o período anterior à fase edipiana, a criança se prepara para o grande rito de iniciação ao mundo da lei e da ordem, ao mundo da "normalidade". Como iniciação, este rito inclui uma prova: o triângulo edipiano, com toda a sua carga de incitamento e interdição. Do sucesso nesta prova dependerá o sucesso do indivíduo. Do sucesso do indivíduo dependerá o sucesso da família e da sociedade.

A força do pai não reside mais no pai concreto, ele não mais encarna o poder dentro da família - pelo menos da forma como o fazia na família

24 PSICOLOGIA CIÊNCIA E PROFISSĀO patriarcal (antigo regime). Muito embora a família machista burguesa tenha preservado algumas de suas prerrogativas, enquanto provedor e representante máximo da família nas relaçőes sociais mais amplas, a força com a qual de fato se conta é a do pai imaginário. Poderíamos também chamar o pai imaginário de "pai social", já que ele pode ser qualquer pessoa, $c$ não apenas o pai biológico. Nos procedimentos judiciais, o técnico procura avaliar os vínculos reais e imaginários para sugerir ao juiz a melhor forma de administrar o pátrio poder, dentro da norma estabelecida. A autoridade paterna, deixando de ser circunstância externa (patriarcalismo), constitui-se em circunstância interna, peça central do mecanismo psíquico sem a qual o indivíduo não será normal, nem estará apto a viver em sociedade.

\section{O trabalhador soclal e os "desvios da norma"}

Baixa tolerância à frustração, insegurança, falta de limites etc... A análise da psique do delinqüente não deixa dúvida de que a grande infração que se pode cometer não é a desobediência em si, mas uma situação edipiana mal resolvida: por isso o infrator contumaz carece de poder paterno, carece de disciplina e interdição, sem o que estará à mercê de seus impulsos anti-sociais. Ou então, numa perspectiva mais liberal, o infrator carece de tratamento, uma oportunidade para reconstruir instâncias de controle psíquico, mal arranjadas por causa de sua inserção em grupos familiares irregularmente constituídos. Finalmente, numa tentativa de abarcar todo o meio social do infrator, procede-se a uma orientação familiar. Estas sāo as três práticas que se entrelaçam na atuação da Justiça de Menores junto às famílias irregulares $e$ seus filhos abandonados, desassistidos e delinquüentes.

$O$ alvo predileto de medidas deste tipo são as chamadas famílias irregularmente constituídas. É nelas que são gerados os pequenos marginais: os trombadinhas, os meninos de rua, os delinqüentes, os menores abandonados etc... Ali vamos atingir os grandes focos da falta de higiene mental, dos grandes desvios da norma. Ali a família edipiana, geradora de indivíduos normais e adaptados, se torna impraticável em função de suas próprias condições de vida.

Os núcleos familiares "desorganizam-se", segundo a ótica da norma, falhando em proporcionar à criança um controle, seja do ponto de vista externo - como na família patriarcal - seja do ponto de vista interno como na família machista. As crianças correm soltas pelas ruas e logo se integram na vida da comunidade mais ampla. Em primeiro lugar, estão expostas ao controle de um maior número de instituições suprafamiliares do que a criança burguesa; além do médico e da escola, as crianças das famílias irregulares estão, desde tenra idade, em contato direto com instituiçöes como a previdência social, a justiça e a polícia, além das obras filantrópicas as mais diversas. Em segundo lugar, para além de todo este controle, elas criam formas próprias de se relacionar com a comunidade: as mães de criação, as hierarquias entre menores, as funçöes, as irmandades de rua etc... Neste quadro, o jogo de interdição e incitamento, para muitos exclusivo do triângulo edipiano, se desvanece ou se estende, provavelmente,por uma gamabem mais ampla de relações.Certamentenãoéo superego burguês que ai se produz. Trata-se de outros tipos de subjetividade, de funcionamento psíquico, irredutíveis a qualquer norma, refratários a qualquer abordagem terapêutica tradicional. Neste terreno movediço, tentam se equilibrar os agentes da normalização.

A orientação familiar deve, sob este ponto de vista, tentar trabalhar com as causas do comportamento desviante do menor - ou seja, com as vicissitudes de uma família desorganizada - para minimizar seus efeitos. Existem, porém, instâncias e regras do jogo familiar que escapam à ótica bidimensional do orientador, tornando sua intervenção estéril nos casos em que elas se fazem decisivas. A impotência do trabaihador social é patente; sua participação, em muitos casos, só tende a agravar a situação.

Se as intervençōes das instâncias macropolíticas, via trabalhador so- 
cial, sobre as famílias, nem sempre são eficazes, o que então sustenta as instituições que delas se ocupam? Talvez a força de um hábito de andar $\mathrm{cm}$ círculos: a divergência leva à vontade de intervir; a intervenção leva à vontade de divergir. Poderíamos questionar a própria consistência de tais vontades. Teriam elas alguma outra função de controle além da normalização ou anormalização?

Quando dizemos que o desvio é expressão negativa de relaçōes sociais vigentes, nós o projetamos na sombra destas relaçöes. Se o tomamos, porém, de uma forma positiva, obteremos que as populações marginalizadas produzem formas de vida que condizem perfeitamente com o melhor padrão de sua condição marginal. As condiçōes do desviante $\mathrm{e}$ do adaptado aqui se confundem. $O$ delinqüente, por exemplo, $\varepsilon$ um desadaptado, do ponto de vista da norma; mas se nos basearmos em sua realidade de vida, ele pode até se tornar um herói, um modelo - como já se tornaram alguns famosos bandidos.

E pela desqualificação que se exerce o maior controle sobre as possibilidades de singularização nos grupos ditos marginais. A situação das familias que os constituem é sempre encarada sob uma perspectiva negativa, a da falta. O que falta a estas famílias, além de condiçōes materiais, são condiçöes morais, psíquicas, intelectuais... falta-lhes até consciência de classe. Ora, tudo o que falta deve ser suprido. Se tudo, porém, é tomado como falta, haja maneiras de suprilas! Se tudo é tomado como falta, a supressão de todas elas é uma tarefa impossivel, um verdadeiro trabalho de Sísifo. O trabalhador social produz assim a sua própria impotência.

Do ponto de vista da população desqualificada, a imagem da faita também $\epsilon$ impotencializadora. Se sua vida é pautada por carências que nada nem ninguém é capaz de suprir, isto produz passividade e desesperança. Na há esforço pela afirmação de suas formas de vida, e sim pela negação destas. A imagem da carência fortalece a imagem da opulência. A população acaba, assim, por se ver com os mesmos olhos daqueles que a desqualificam. Há também aqui um en- fraquecimento enquanto grupo, na correlação de forças sociais que se embatem. Ele ocorre em função da dependência em relação a outras categorias sociais que, supostamente, detêm os meios para suprir as faltas. Espera-se o líder ou a instituição que salvará a sociedade, isto é, suprirá todas as suas carências. A cada mudança de governo, porém, uma nova decepçäo vem confirmar que, realmente, a situação não tem jeito.

As vontades de integração social e de normalização têm, como ponto de apoio, o embate das forças sociais em conflito. As instituições encarregadas de tal controle não podem dar conta de duas tarefas opostas: preservar-se enquanto instituição e extingüir as causas de sua existência. Neste impasse, qual o lado que prevalece? Basta observar os resultados: a divergência permanece, ajudando assim a perpetuar a instituição. A elite tecnocrata que atua nas instituições não interes-

\section{Contraponto}

\section{Genaro Ieno Neto \\ Depto. de Psicologia Universidade Federal da Paraíba}

A intranqüilidade que a autora do artigo acima expressa não é dela só e nem é produto apenas dos "dias de hoje": qual o nosso papel enquanto técricos assalariados de instituiçōes públicas ou privadas frente ao conflito entre os interesses dessas instituiçōes, que pagam nosso trabalho, $e$ as expectativas da clientela sobre a qual devemos excercer nossa prática profissional? Devemos optar por um dos pólos do conflito ou servir de intermediação entre eles?

Essas questōes vêm sendo discutidas e enfrentadas em uma área de atuação, a Educação Popular, há pelo menos vinte e cinco anos: qual o papel do educador junto às camadas populares de nossa sociedade? As respostas a essas questões têm sido dadas diferentemente, conforme a conjuntura política do País e a opção política do educador no que diz respeito a que tipo de interesses ele está disposto a servir em sua prática educativa.

A palavra política aparece no centro da caracterização das condi- sa, portanto, acabar com os desvios e sim administrá-los.

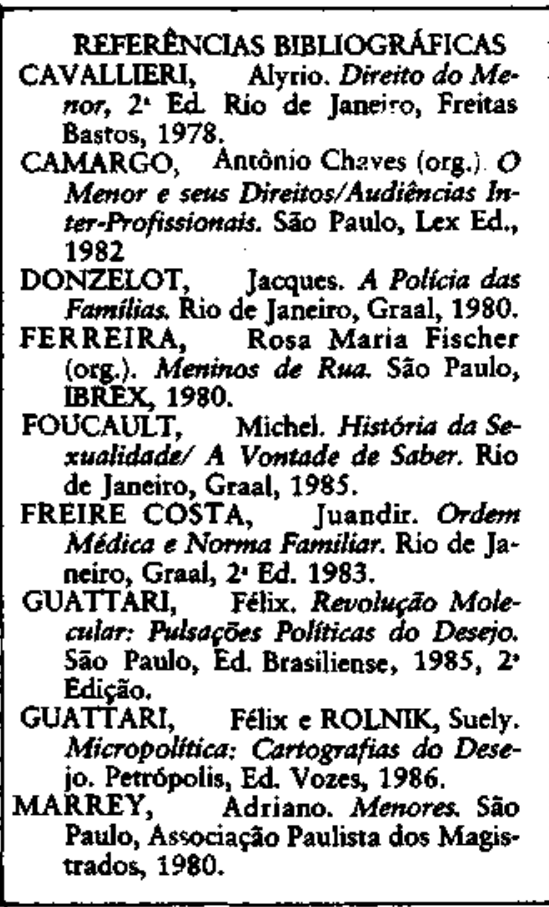

CAMARGO, Antônio Chaves (org.) $O$ Menor $e$ seus Direitos/Audiencias In1982

DONZELOT, Jacques, A Polticia das RREIRA, Rosa Maria Fischer (org.). Mentinos de Rua São Paulo, IBREX, 1980.

$x$ walidadef A Vontade de Saber. Rio de Janeito, Graal, 1985.

Médica e Nomma Familiar. Rio de Janeiro, Graal, 2' Ed. 1983. Sāo Paulo, Ed. Brasiliense, 1985, 2' Edição.

Micropolitica: Cartografias do Dese, Cozes, 1986.

Patılo, Associaçâo Paulista dos Magistrados, 1980 